\title{
Maquiavelo y la razón de Estado en dos obras dramáticas de Calderón de la Barca
}

\author{
Julio Juan RUIZ \\ Universidad Nacional de Mar del Plata \\ Juliojro7@yahoo.com.ar
}

\begin{abstract}
RESUMEN
Pese a la presencia de la censura, la escena teatral, en la España del Siglo de Oro, fue un espacio privilegiado para la manifestación de las cosmovisiones políticas que emergieron conjuntamente con el Estado Moderno: la doctrina de Nicolás Maquiavelo y la razón de Estado. La primera proclamó la autonomía de lo político, mientras que la segunda esbozó los medios para afianzar el poder del Estado. En el presente trabajo, nos proponemos analizarlas en dos de las obras más celebres de Calderón: La vida es sueño y La hija del aire. En ambas obras, también se manifiesta un profundo pensamiento ético; el cual, en los albores de la modernidad, denunció los abusos del poder.
\end{abstract}

Palabras claves: Calderón, Maquiavelo, Estado, Poder.

\begin{abstract}
Despite the presence of censorship, the theater scene in the Spain of the Golden Age, was a privileged space for the manifestation sides political worldviews that emerged in conjunction with the Modern State: Nicolás Maquiavelo's doctrine and reasons of state.

The first proclaimed the autonomy of politics, while the second outlined the means to strengthen state power. In this paper, we propose to analyze two of the most famous tragedies Calderón: La vida es sueño and La Hija del Aire. In both works, also manifest a profound ethical thought, who, at the dawn of modernity, denounced the abuses of power.
\end{abstract}

Key words: Calderón, Maquiavelo, State, Power.

Sumario: 1. Introducción. 2. La razón de Estado y la libertad. 3. El poder y sus armas. 4. Conclusión 


\section{Introducción}

Hace varias décadas, el historiador José Antonio Maravall observó que no se puede entender al hombre moderno sin el Estado. En efecto, este emergió en el Renacimiento y posibilitó la concentración del poder en manos del monarca.

Esta nueva forma de organización jurídica y política de los antiguos reinos, estuvo caracterizada por una racionalidad opuesta a la medieval. En esta, el rey, según el Opúsculo para el gobierno de los príncipes de Tomás de Aquino, debía conducir al hombre a su finalidad: la vida eterna; mientras que en el plano terrenal se conformaba con vivir honestamente. En la Modernidad, esta cosmovisión teológica fue suplantada por otra: el realismo político moderno, cuyas manifestaciones más eminentes fueron el pensamiento de Nicolás Maquiavelo y la doctrina de la razón de Estado. Esta última no se interesaba por el fin del hombre, sino por las exigencias necesarias para afianzar la estabilidad política de las incipientes naciones. A su vez, si bien esta doctrina se basó en el pensamiento del filósofo florentino, se diferenció de esta en que no se ocupó de discernir las estrategias adecuadas para la adquisición y conservación del poder por el príncipe, sino en la existencia y naturaleza del Estado y, fundamentalmente, en afianzarlo como única instancia de poder que garantizara la paz social, independientemente de toda consideración jurídica o moral. Por este motivo, fue "contra una tradición cristiana y judicial, que consideraba al gobernante como justo y que respetaba todo el sistema jurídico".

En la España del Siglo de Oro, la oposición entre la cosmovisión política moderna y la medieval puede ser observada con claridad, porque el Estado se asentó "sobre una base de supervivencias tradicionales que se dan en todas las esferas" ". En este sentido, en la península ibérica, las nuevas corrientes filosóficas coexistieron con un sistema de pensamiento anclado en la escolástica medieval, como la filosofía neoescolástica del jesuita Francisco Suárez.

En relación con el realismo político moderno podemos distinguir un espectro doctrinario amplio, el cual va desde un planteamiento ético, propiciado por los que Javier Peña Echeverría (1978) denomina eticista, a otro diametralmente opuesto denominado tacitista. Esta última corriente postuló la autonomía de lo político sin confrontarla con la ortodoxia religiosa. Dentro de este grupo sobresalió Furió Ceriol y Álamos Barrientos. En medio de estas posturas antagónicas podemos vislumbrar una tendencia intermedia conformada por autores que trataron de reconocer una cierta autonomía de lo político, pero con sujeción y subordinación a los límites de la ortodoxia como Baltasar Gracián y Diego de Saavedra Fajardo.

Lo que más irritó a los pensadores políticos españoles fue el uso instrumental de la religión, expuesta en sus Discursos sobre la Primera Década de Tito Livio. En

${ }^{1}$ M. Foucault (1996), p.49.

${ }^{2}$ J. A. Maravall (1972), p.18. 
esta obra al analizar la función que cumplió la religión en Roma, propició un uso instrumental de esta. Por este motivo, los escritores católicos se propusieron esbozar una razón de Estado subordinada a la religión o al menos, respetuosa de sus límites. Así, Pedro de Rivadeneira exhortaba al monarca a que: "[...] no se haga censor de la fe ni juez de la religión, ni superior de causas y ministro de la Iglesia, pues no lo es, sino hijo de ella y defensor". A su vez, esta razón de Estado anatematizó las pautas de acción aconsejadas por Maquiavelo, porque: “[...]Dios nuestro Señor (que es un bien infinito y simplísimo) aborrece y castiga con su mano fuerte a todos los príncipes hipócritas que quieren engañar con máscara de virtud ${ }^{3 "}$. También Baltasar Gracián censuró los lineamientos del filósofo italiano, pues consideró que: "[...] vulgar agravio es de la política el confundirla con astucia: no tiene por sabio sino al engañoso, y por más sabio el que más supo fingir, disimular, engañar",

Los teóricos españoles optaron por el mismo terreno que su adversario: la historia. Fundamentalmente, analizaron la obra de los grandes historiadores clásicos como Cornelio Tácito. En este sentido, Christoph Strosetzki marca que "el gran interés en los historiadores de la Antigüedad partió de la idea de que la naturaleza del hombre es constante y de que, por ello, se puede aprender de la historia ${ }^{5 "}$. Este valor pedagógico está presente en la obra de Diego de Saavedra Fajardo, Idea de un príncipe político cristiano representada en cien empresas, dedicada al primogénito de Felipe III, el príncipe Baltasar Carlos Domingo, quien murió a los dieciséis años. Así, el escritor y diplomático señaló que los malos gobiernos del pasado prestan un gran servicio, porque: "[...] sólo este bien queda de haber tenido un príncipe malo, en cuyo cadáver haga anatomía la prudencia, conociendo por él las enfermedades de un gran mal para curarlas ".".

Estas cosmovisiones contrapuestas se manifiestan en forma dialéctica en dos de las obras más célebres de Calderón: La vida es sueño y La hija del aire. Esta oposición encuentra una síntesis en el pensamiento político del dramaturgo español, caracterizado por profundas convicciones éticas.

En el presente artículo nos proponemos analizar la relación dialéctica entre concepciones filosóficas opuestas en el teatro de Calderón. De este modo, pierde sentido el perfil que, durante mucho tiempo, le ha atribuido parte de la crítica como un escritor reaccionario, al servicio de los intereses de la monarquía. En este sentido en su dramaturgia, las cosmovisiones sobre el poder "traspasaron los géneros de la filosofía política para manifestarse en acciones de teatro, con público masivo que

\footnotetext{
${ }^{3}$ P. De Rivadaneira (1998), p.17.

${ }^{4}$ B. Gracián (2009), p. 129.

${ }^{5}$ C. Strosetzki (2005), p. 539.

${ }^{6}$ D. de Saavedra Fajardo (1927), p. 110.
} 
podía presenciar tiranicidios y rebeliones en escena" ${ }^{7}$. Así, de un modo sutil, la escena manifestaba los límites del poder.

\section{La razón de Estado y la libertad}

En la política medieval, la acción del monarca estaba ajustada al orden jurídico objetivo. Esta realidad se plasmó en la concepción del rey justo, que legitimó el poder del monarca en el derecho. Esta legitimación fue profundamente analizada en una obra clásica de la filosofía medieval: Los dos cuerpos del rey de Ernst Kantorowicz. En la primera parte de este texto se estudió la concepción cristocéntrica del poder, la cual fusionó gracia y naturaleza. En este sentido, debemos observar que esta concepción política, litúrgica y teológica, no estuvo vigente en la Alta Edad Media española. En efecto, los reyes de la península ibérica no necesitaron legitimar su poder en lo sobrenatural. Por esta razón, la ceremonia de unción real fue abolida en los reinos de Castilla y de León ${ }^{8}$. No obstante, sí legitimaron su autoridad en el derecho, tal como lo prueban Los Fueros y, fundamentalmente, Las Siete Partidas de Alfonso X, el Sabio.

En Europa, la transición entre una concepción teológica del poder y otra más jurídica se realizó en la Baja Edad Media. En efecto, en esta época se sustituyó la noción de monarquía cristocéntrica y litúrgica, por otra, más teocrática y jurídica. Este cambio se manifestó en el Policraticus de Juan de Salisbury, obra que estuvo dedicada a Santo Tomás Becket, arzobispo de Canterbury, con quien colaboró el filósofo inglés. Este texto es una síntesis del pensamiento medieval. Así, para su autor, no es el príncipe quien gobierna, sino, por su intermedio, la justicia, tal como lo enseñaba el Derecho Romano. Si bien no fue un jurista profesional, conocía y manejaba el Digesto, recopilación sistemática de los textos de la doctrina romana del período clásico, ordenada por el emperador Justiniano. Posteriormente, Juan de Viterbo introdujo en su Espejo de la Potestad el análisis del texto de la Novela $108,{ }^{9}$ en el que se consideraba que Dios envió al Príncipe a los hombres como ley animada. Sobre estos fundamentos se afianzó la concepción jurídica y secular. Asimismo, debemos señalar que en la Baja Edad Media, Europa estuvo unida por una cultura común, que entrelazó lo jurídico y lo teológico:

${ }^{7}$ I. Arellano 82006), p. 12.

${ }^{8}$ J.A. Maravall (1970).

${ }^{9}$ Después de publicado el Digesto, en el año 533, se publicaron nuevas leyes, a las que se las llamó Novellae; es decir, Novelas. Estos textos regularon disposiciones complementarias, pero, en algunos otros, legislaron sobre instituciones jurídicas fundamentales. El emperador quiso compilarlas, pero no logró hacerlo. Fueron publicadas en una serie de colecciones, de las cuales, la más antigua es la llamada Epitome Juliani. Ver: V. Arangio Ruiz (1980). 
[...] Es esta unidad de la cultura la que explica por que Derecho y Religión estaban tan íntimamente relacionados en la tardía literatura medieval. A veces la mezcla del Derecho Romano y la Teología conduce a un resultado que, a los ojos modernos acostumbrados a la separación de cada disciplina, parecen extraños ${ }^{10}$.

Si bien los textos del Corpus Iuris fueron una fuente común, pues lo estudiaban tanto civilistas como canonistas, en la segunda mitad del siglo XIII otro texto adquirió la misma importancia: la Ética Nicomaquea de Aristóteles. En éste se consideró que: "[...] la justicia es algo intermediario al igual que el juez, quien es la justicia viviente ${ }^{11 \%}$. Esta condición se reservó para el monarca. La obra de Aristóteles fue profundamente estudiada por el discípulo y seguidor de Santo Tomás, Gil de Roma, quien, en 1279, dedicó su tratado político De regimine principum a Felipe el Hermoso, futuro rey de Francia. En base a la doctrina del Estagirita, el filósofo medieval concluyó que: “[...] el gobernante es el intermediario entre el Derecho Natural y el Derecho Positivo ${ }^{12}$ ".

La concepción de la potestad regia como intermediaria entre la Ley Natural y la Positiva subsistió aún con el advenimiento del Estado Moderno, donde el poder del rey se justificó en la Teoría de la Soberanía de Jean Bodin, cuyos fundamentos podemos analizarlos en su obra Seis libros de la República. En la teoría del legista francés, el que hace las leyes, el soberano, no podía estar subordinado a estas, sino que permanecía en un plano superior. Por esta razón, el monarca "está sólo sometido a las leyes divinas y naturales ${ }^{13}$ ". Sin embargo, la racionalidad política moderna consideró que la seguridad del Estado estaba por sobre todo impedimento. Esta concepción del poder se manifestó en La vida es sueño. En efecto, Basilio, el autócrata soberano del imaginario reino de Polonia, en pos del bien de su patria, privó a Segismundo, su legítimo heredero, del derecho más preciado: la libertad. Esta decisión violó el Derecho Natural, el cual, según el pensamiento escolástico de la Edad Media, es conocido por los hombres a través de la razón. Este ordenamiento estaba compuesto por derechos esenciales, a los cuales, en el constitucionalismo moderno, se los conoce como derechos fundamentales.

Si nos focalizamos en la decisión arbitraria del monarca anciano y sabio, observamos que esta se legitimó en la ciencia. Sus estudios le revelaron que su heredero sería: " el hombre más atrevido, / el príncipe más cruel / y el monarca más

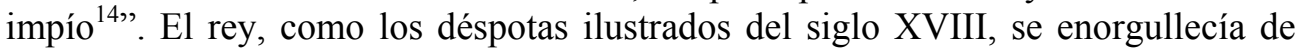
sus estudios: "ya sabéis que son las ciencias / que más curso y estimo / matemáticas sutiles, / por quien al tiempo le quito, / por quien a la fama rompo / la jurisdicción y

${ }^{10}$ G. Stein (2001), p.103.

${ }^{11}$ Aristóteles (2008),p.134.

${ }^{12}$ E. Kantorowicz (1985), p.136.

${ }^{13}$ G. Del Vechio (1942), p.90.

${ }^{14}$ P. Calderón (2003), p.128. 
oficio / de enseñar más cada día ${ }^{15}$ ". Sentía una profunda veneración por la astrología: "le gano al tiempo / las gracias de contar lo que yo he dicho" ${ }^{16 "}$. En base a lo dictaminado por las estrellas, ordenó el encierro de su hijo en una torre, situada en los montes, donde Clotaldo, su fiel colaborador, "le ha enseñado ciencias; / éste en la ley le ha instruido / católica, siendo solo / de sus miserias testigos ${ }^{17 "}$.

En la torre, Segismundo era acuciado por el deseo de saber: "iqué delito cometí / contra vosotros naciendo! ${ }^{18 "}$. Esta indagación manifestaba su dolor, porque al observar el puesto del hombre en la Creación, comprobó que, si bien tenía más alma que el ave y menos instinto que el bruto, no podía entender por qué carecía de libertad. Este atributo esencial, en el Discurso sobre la Dignidad del Hombre define lo humano:

\begin{abstract}
Así pues, a todas las demás creaturas le son dadas, de una vez para siempre, su ser y su consecuente obrar; sólo el hombre puede y debe, en un sentido u otro, hacerlos suyos, precisamente mediante el ejercicio de su libertad. En efecto, a lo largo de su existencia ha de ir esculpiendo su propio perfil a través de las elecciones que resultan de tal albedrío. Este se articula sobre la base de su inteligencia y su voluntad, pero opera sobre una suerte de bloque de mármol originario en el que cada uno realiza su propia escultura ${ }^{19}$.
\end{abstract}

Consciente de su dignidad, él se preguntaba: “¿y yo, con más albedrío, / tengo menos libertad? ?" ". Esta situación injusta lo llevó a la más profunda desazón: "quisiera sacar del pecho / pedazos del corazón ${ }^{21}$. A su vez, esta realidad, un verdadero secreto de Estado, salió a la luz por el conflicto sucesorio entre los dos sobrinos de Basilio: Astolfo y Estrella, quienes fueron convocados al palacio.

En la corte, el anciano rey, pronunció ante los dos contendientes un solemne discurso, en el que justificó su decisión y sentó las bases para dirimir el conflicto por el trono. Así, dejó claras tres razones que lo condujeron a privar de su libertad al príncipe. En la primera, prevaleció el amor por su patria: "os quiero librar / de la opresión y servicio / de un tirano ${ }^{22 \%}$; en la segunda, manifestó ser consciente de la violación de la ley natural: " si a mi sangre le quito / el derecho que le dieron / humano fuero y divino, / no es cristiana caridad, / pues ninguna ley ha dicho / que, por reservar yo a otro / de tirano y atrevido, / pueda yo serlo ${ }^{23}$ ”; por último, en la

\footnotetext{
${ }^{15}$ P. Calderón (2003), pp.127-128.

${ }^{16}$ P. Calderón (2003), p. 123.

${ }^{17}$ P. Calderón (2003), p. 130.

${ }^{18}$ P. Calderón (2003), p. 92.

${ }^{19}$ G. P. Della Mirándola (2008), p. 167.

20 P. Calderón (2003), p. 95.

${ }^{21}$ P. Calderón (2003), p. 96.

${ }^{22}$ P. Calderón (2003), p. 130.

${ }^{23}$ Ibídem.
} 
tercera, manifestó su honestidad intelectual, pues, como astrólogo bien sabía que: "el hado más esquivo, la inclinación más violenta, / el planeta más impío / solo el albedrío inclinan, / no fuerzan el albedrío ${ }^{24,}$.

Después de exponer estas razones, como buen científico, decidió verificar su hipótesis: el cielo no miente. En pos de su refutación o confirmación, manda a traer al príncipe al palacio, para que: “ [...] haga/ de su talento la prueba. / Si magnánimo se vence, / reinará; pero si muestra / el ser cruel y tirano, / le volveré a su cadena ${ }^{25}$ ". En este sentido, podemos observar que el listón estuvo alto, pues, de quien ha sido "cortesano de unos montes" no se puede esperar que actúe "prudente, cuerdo y benigno", puesto que tanto la prudencia como la cordura y la benignidad son virtudes que se adquieren en la vida social. En la sociedad es donde el ser humano desarrolla su verdadera naturaleza, tal como lo expuso Aristóteles en La Política: "[...] así como el hombre perfecto es el mejor de los animales, así también, apartado de la ley y de la justicia, es el peor de $\operatorname{todos}^{26}$ ". En este sentido, Segismundo manifestó en la corte su naturaleza indómita. Así, por ejemplo, al saber su identidad condenó a Clotaldo a muerte. Esta decisión, si bien fue arbitraria, no lo fue su fundamentación: "en lo que no es justa ley, no ha de obedecer al Rey; / y su príncipe era $\mathrm{yo}^{27}$ ". Este principio jurídico esencial es refutado por un criado: "él no debió examinar / si era bien hecho o mal hecho ${ }^{28 \%}$. De este modo, esta confrontación nos introduce en un debate sobre la obediencia debida a la autoridad. Una obediencia ciega de los subordinados menoscaba su dignidad. Por otra parte, como lo señala José Alcalá Zamora y Queipo de Llano, este diálogo fue subversivo y pasó la censura porque se creyó que este demostraba "el talante energuménico del Segismundo de la fase palaciega o tal vez por su talante doctrinal con escasas posibilidades aparentes[...] de transformarse en bandera sediciosa ${ }^{29}$.

Fundamentalmente, el comportamiento del malogrado heredero se caracterizó por su arbitrariedad: "Nada me parece justo / en siendo contra mi gusto ${ }^{30 "}$. En su comportamiento prevaleció la pasión. Este modo de actuar, en la obra del escritor y diplomático español, don Diego Saavedra Fajardo, Idea de un príncipe político cristiano representada en cien empresas ${ }^{31}$, sirve como test para distinguir al buen gobernante del tirano. En efecto, él observó que, en el déspota, priman las pasiones:

\footnotetext{
${ }^{24}$ P. Calderón (2003), p. 132.

${ }^{25}$ P. Calderón (2003), p. 149.

${ }^{26}$ Aristóteles (1999), p. 52.

${ }^{27}$ P. Calderón (2003), p. 161.

${ }^{28}$ P. Calderón (2003), p. 161.

${ }^{29}$ J. Alcalá Zamora y Queipo de Llano (2009), p. 126.

${ }^{30}$ P. Calderón (2003), p. 167.

31 Esta obra estuvo dedicada al hijo de Felipe IV, el príncipe Baltasar Carlos Domingo, quien al fallecer a los dieciséis años no pudo mostrar los frutos de las enseñanzas de su maestro.
} 
"[...] en su pecho se levantan tempestades furiosas de afectos, con las cuales perturbada y ofuscada la razón, desconoce la verdad y aprehende las cosas, no como son, sino como se las propone la pasión ${ }^{32 \%}$.

Pese a su derrota, pues aparentemente se confirmó la hipótesis del cielo, Segismundo tomó conciencia de su identidad: "[...] pero ya informado estoy / de quien soy, y sé que soy / un compuesto de hombre y fiera" ${ }^{33}$ ". Un "compuesto de hombre y fiera" es, según Althusser ${ }^{34}$, la naturaleza orgánica del modelo de hombre de Estado propuesto por Maquiavelo, desarrollada en el célebre capítulo XVIII de El Príncipe. En efecto, el filósofo florentino, por medio de la figura del Centauro, mitad hombre, mitad bestia, esbozó la naturaleza del poder:

[...] Deben saber ustedes, entonces, que hay dos modos de combatir: uno con las leyes, otro con la fuerza. El primero es propio del hombre, el segundo de las bestias. Pero como el primero muchas veces no basta, conviene recurrir al segundo. Por lo tanto, a un príncipe le es necesario saber usar bien a la bestia y al hombre ${ }^{35}$.

Actuar como hombre significaba gobernar según las leyes, mientras que como bestia, según la fuerza. En este sentido, el desdichado heredero debió domesticar la fiera que había en él, porque la imagen de príncipe que en la obra se privilegió fue la estoica. Para aquella corriente filosófica, el hombre debe vencer sus pasiones, porque nublan el juicio. Por este motivo, en sus Empresas Políticas, Saavedra Fajardo esbozó un programa pedagógico, cuyo destinatario fue el primogénito de Felipe IV, el cual tuvo como objetivo principal: "[...] que en sus acciones [el príncipe] no se gobierne por sus afectos, sino por razón de Estado ${ }^{36 \%}$. Cabe acotar que, para el diplomático y escritor español, gobernarse según la razón de Estado significaba someter los afectos y las pasiones a los dictámenes de la razón.

Por su comportamiento despótico, Segismundo vuelve a ser encerrado. Al despertar, desaparecieron las certezas de su vida en la corte y, por esta razón, puso en duda la realidad: "porque si ha sido soñado / lo que vi palpable y cierto, / lo que veo será incierto ${ }^{37 \%}$. A su vez, esta duda no lo conduce como a Descartes a un cuestionamiento metafísico de la existencia, sino a una conversión ética: "[...] pues reprimamos / esta fiera condición, / esta furia, esta ambición / por si alguna vez soñamos ${ }^{38 ”}$. En su prisión, llega a una iluminación: “ y en el mundo, en conclusión,

${ }^{32}$ D. de Saavedra Fajardo (1927), p. 129.

${ }^{33}$ P. Calderón (1929), p.229.

${ }^{34}$ L. Althusser (2004).

${ }^{35}$ N. Maquiavelo (2008), p. 160.

${ }^{36}$ D. de Saavedra Fajardo (1927), p. 33.

${ }^{37}$ P. Calderón (2003), p.207.

${ }^{38}$ P. Caderón (2003), p.209. 
/ todos sueñan lo que son"39. Mientras tanto, el pueblo se rebelaba contra Basilio por nombrar heredero a Astolfo: "y el vulgo, / penetrando ya y sabiendo / que tiene

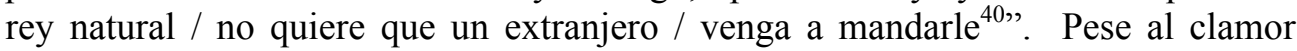
popular, Segismundo no se deja seducir, porque aprendió que las ambiciones de poder no son mas que "fantásticas ilusiones / que al soplo menos ligero / del aura han de deshacerse ${ }^{41 \%}$. De este modo, palpó lo efímero de sus antiguos anhelos de poder. Al ser consciente de esta realidad, se propuso: "obrar bien; / pues no se pierde / obrar bien, aún entre sueños ${ }^{42}$,"

Su triunfo sobre las huestes de Basilio concordó con los vaticinios del hado, mas no su conversión. Así, contradiciendo a las estrellas, perdonó a su padre y le enseñó que: "la fortuna no se vence / con injusticia y venganza; porque antes se incita más ${ }^{43}$ ”; y a esta solo se la vence "con prudencia y templanza ${ }^{44,}$. Por esto el trágico heredero tuvo que aprender a dominarse a sí mismo $\mathrm{y}$, por sobre todo, a perdonar. A través de su clemencia, "el problema de la voluntad como estructura afectiva del poder queda unido además al problema familiar entre el padre y el hijo 45". A su vez, desde una perspectiva política concordamos con Ignacio Arellano cuando observa que la obra no denuncia el sistema monárquico, sino "[...] el ejemplo de un mal rey que incurre en graves errores debidos a un defecto trágico de soberbia y al intento de indagar en un territorio prohibido a los conocimientos mortales ${ }^{46 \%}$.

En suma, en el vértice del poder se deseó establecer una efigie modélica: la de un príncipe estoico, señor de sus pasiones. Esta figura contrastó con la marcada ambición de poder que caracterizó al hombre moderno desde el Renacimiento.

\section{El poder y sus armas}

Las obras políticas de los escritores del Siglo de Oro español, anatematizaron la doctrina de Maquiavelo. Sin embargo, detrás de la ortodoxia religiosa, sus doctrinas abordaron intereses y expectativas concretas. En este sentido, podríamos decir que se ubicaron en un horizonte empírico, cuyo origen se encuentra el pensamiento del filósofo italiano. Esta perspectiva epistemológica influyó en el pensamiento político europeo. Así, después de Aristóteles él sentó las bases de la Ciencia

\footnotetext{
${ }^{39}$ P. Calderón (2003), p. 210.

${ }^{40}$ P. Calderón (2003), p.218.

${ }^{41}$ P. Calderón (2003), p. 220.

${ }^{42}$ P. Calderón (2003), p.223.

${ }^{43}$ P. Calderón (2003), p. 265.

${ }^{44}$ P. Calderón (2003), p. 265.

45 G. Poppenberg (2011), p.292.

${ }^{46}$ I. Arellano (2006), pp.152-153.
} 
Política ${ }^{47}$. Este empirismo puede ser constatado en el siguiente pasaje de $E l$ Principe:

Pero mi intención es escribir algo útil para quien lea, y entonces me ha parecido más conveniente seguir la verdad real de la cosa y no su representación imaginaria $[. .$.$] porque el modo en que se vive y el modo en que se debería vivir$ están tan lejos el uno del otro, que si alguien deja a un lado lo que se hace por lo que se debería hacer aprende más su ruina que su preservación: un hombre que quiere profesar de bueno en todos los aspectos, sólo logrará su ruina entre tantos que no lo son. Por lo tanto un príncipe, si quiere conservarse, debe aprender a poder ser no bueno, y valerse de ello o no según la necesidad ${ }^{48}$.

En el pensamiento del florentino, el accionar del príncipe, el hombre de Estado por excelencia, está más allá de las categorías morales de virtud y vicio. Por eso, solo puede ser juzgado a partir de un criterio: el éxito, en el que sólo cuenta el resultado. En este ethos teleológico sobresale lo que denominó el buen uso del mal. En efecto, al estudiar la acción política de Cesar Borgia, señor de la Romaña Italiana e hijo del Papa Alejandro VI, constata la presencia del mal en el gobierno y, paradójicamente, lo que él denominó como el buen uso del mal; es decir, del mal necesario para conservar el Estado. En este sentido, expresó que: "[...] podemos considerar bien empleado aquellas crueldades que se ejercen de golpe y de una sola vez, por la necesidad de asegurar el poder ${ }^{49}$ ". Por esta razón, el duque Valentino, frente a los abusos acaecidos en sus dominios, puso al frente del gobierno a un hombre cruel y despiadado, Ramiro de Lorca, para que reprendiera los delitos y desmanes. Una vez pacificada la región, ejecutó a su lugarteniente en la plaza pública, para indicar el fin del terror y el comienzo de un tiempo de paz. De este modo, César empleó solo el mal que era necesario. Por el contrario, el filósofo florentino enseñó que quien abuse del mal se convierte en tirano, e, inevitablemente, sucumbe ante la rebelión popular, lo cual él comprobó en la historia romana y en la de los estados italianos del Renacimiento. Esta realidad se manifiesta en la obra La hija del aire, donde la heroína, Semíramis, se despeña desde lo más alto del poder, el trono, como consecuencia de su accionar despótico y violento.

Desde una perspectiva estructural, esta tragedia puede ser dividida en dos partes: la primera nos muestra el ascenso de la heroína al poder, y la segunda su trágica caída. Estas se encuentran unidas por el hado fatal, que anuncia el infausto destino, pues la heroína sabía que por ella habría: " tragedias, muertes, insultos, / ira, llanto

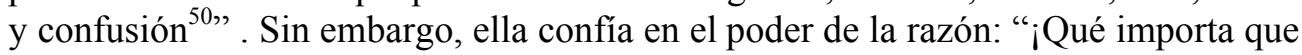

\footnotetext{
${ }^{47}$ J.A. Maravall (1984).

${ }^{48}$ N. Maquiavelo (2008), pp. 148-149.

${ }^{49}$ N. Maquiavelo (2008), p. 115.

${ }^{50}$ P. Calderón (2009), p. 74.
} 
mi ambición / digan que ha de despeñarme / del lugar más superior / si para vencerla a ella / tengo entendimiento yo! ${ }^{51 "}$. En este sentido, su derrota nos demuestra lo irracional de su pasión por el poder.

Semíramis como Segismundo, pertenecen a la categoría de héroes signados por la violencia antes de su nacimiento. En efecto, fue concebida con ferocidad al ser producto de la violación cometida por su padre, quien luego muere asesinado por su víctima; a su vez, ella, al nacer, provoca la muerte de su madre, una ninfa de la diosa Venus. Alegóricamente, esta realidad se manifiesta en el mote "víbora humana". El mal que la acompañó desde su venida al mundo se incrementará en los hechos violentos, los cuales signaron su ascenso al poder: el destierro y suicidio de Menón, su primer enamorado, y el posterior asesinato de su esposo, el rey Nino. Sin embargo, pese a ser culpable de estos actos funestos, la heroína cuenta con la protección de los dioses: "Hija soy de Venus, y ella / mi fortuna favorece" Amparándose en esta protección sobrenatural, logró ser coronada.

Fundamentalmente, en el plano argumental sobresalen dos juegos de opuestos. En el primero se manifiesta el par fortuna / razón, mientras que en el segundo, fortuna / justicia. Ambos se entrelazan en el trágico sino de Semíramis. Si comenzamos por el primero, observamos que en este se evidencia un sutil juego de espejos que marca la diferencia entre Lidoro, un rey vasallo, leal a su marido y ella, quien le dio muerte. El primero, para desagraviar al monarca desparecido, la desafió al combate: "[...] para que el cielo y la tierra / vean cuanto soy tu opuesto; / pues tú, como fiera ingrata, / quitas la vida a tu dueño, / y yo, como can leal, / le sirvo después de muerto ${ }^{53}$ ". Tras la batalla se asistió al triunfo de la fortuna sobre la razón; es decir, la victoria de la heroína y la derrota del rey justo. Ella cobró venganza de su enemigo: "[...] tiranías no serán / que yo en esta parte quiera, / procediendo como fiera, / tratarte a ti como can ${ }^{54,}$. No obstante, pese a su proceder tiránico, la valentía de la reina genera admiración; así, Chato, el bufón testigo de su destino expresó: " $i C o n$ que grande majestad / vuelve a la ciudad triunfante / esta altiva, esta arrogante / hija de su vanidad! ${ }^{55 " . ~ A s i ́, ~ a d e m a ́ s ~ d e ~ s u ~ b e l l e z a, ~ l a ~ s o b e r a n a ~}$ era ponderada por su fuerza, pues fue una "reina andrógina, capaz de subyugar a los hombres con el amor y con el valor ${ }^{56 "}$.

Paradójicamente, el día de su victoria el pueblo aclama al príncipe y quiere a Ninias, el legítimo heredero: "no dejemos ya regirnos / de una mujer, pues tenemos / Príncipe tan grande ${ }^{57 ”}$. Ella indignada consulta con sus consejeros. Así, Licas,

${ }^{51}$ P. Calderón (2009), p. 74.

${ }^{52}$ P. Calderón (2009), p. 187.

${ }^{53}$ P. Calderón (2009), p. 208.

${ }^{54}$ P. Calderón (2009), p. 217.

${ }^{55}$ P. Calderón (2009), p. 221.

${ }^{56}$ M.G. Profeti (2010), p.20.

${ }^{57}$ P. Calderón (2009), p. 223. 
atinadamente, le planteó la realidad: "mas si el Príncipe es, señora, / de mi rey natural hijo / y tiene razón el pueblo, / ¿quién bastará reducirlo? ${ }^{58 " . ~ N o ~ o b s t a n t e, ~ l a ~}$ reina puede aplastar al pueblo por la fuerza, pero decide retirarse del gobierno y planear otro castigo: " pero quiero de vosotros / tomar, con mejor estilo, / mejor venganza" ${ }^{59}$ ". Por esta razón, decidió dejar el gobierno, mas no el poder: "el más culto retiro / de este palacio será / desde hoy sepulcro mío, / adonde la luz del sol / no entrará por un resquicio ${ }^{60}$,

En este ostracismo planificó su venganza. Sin embargo, lo peculiar de esta es que recurre a un sutil ardid; es decir, en términos de Maquiavelo, a la astucia. Podemos notar que hay un refinamiento de su maldad, pues, a diferencia de la fuerza, el ardid requiere de ingenio. En este sentido, Althusser ${ }^{61}$, al analizar el célebre capítulo XVIII de El Príncipe, señaló que la oposición leyes / artimañas es flagrante: "todos sabemos cuán loable es en un príncipe mantener la palabra dada y vivir con integridad [conforme a las leyes] y no con artimañas y engaños ${ }^{62 \%}$. Según el filósofo francés, la artimaña es "el arte de fingir que se observan las leyes violándolas totalmente o torciéndolas. Es la necesidad y la inteligencia del no ser bajo las apariencias del ser, y viceversa ${ }^{63}$. . A través del juego de las apariencias, decidió suplantar a su hijo, quien guardaba un gran parecido físico con ella. Así, pensó que: "podré, ciego, traerle, / donde el sol otra vez no llegue a verle ${ }^{64 "}$. Este plan manifiesta una audacia extrema: "Fortuna, si a los osados / se dice que favoreces / yo lo soy ${ }^{65}$ ",

Al retomar el poder, ella cree vencer todas las sospechas: "mi ingenio las desvanece, porque ya ninguna toca / en lo principal, pues creen / que soy Ninias ${ }^{66 "}$. Sin embargo, su proceder genera inquietud. En este sentido, Lisías le advierte que con sus decisiones pasa de un extremo al otro, pues castigó al soldado, a quien Ninias había premiado, por haberle aclamado como rey. Además, hizo de Friso, antes su enemigo, su allegado más próximo, y se aparta de Licas, el preferido de su hijo, entre otros actos que generaban asombro en el círculo de cortesano más próximo. No obstante, lo que más desconcertó fue el valor que demostró al enterarse del inminente arribo de tropas enemigas: “iQué fingido valor ${ }^{67}$ !". Todos sabían que Ninias no era belicoso. Estas huestes estaban conducidas por Irán, hijo

\footnotetext{
${ }^{58}$ P. Calderón (2009), p. 225.

${ }^{59}$ P. Calderón (2009), p.226.

${ }^{60}$ P. Calderón (2009), p.226.

${ }^{61}$ L. Althusser (2004).

${ }^{62}$ N. Maquiavelo (2008), p. 112.

${ }^{63}$ L. Althusser (2004), p. 122.

${ }^{64}$ P. Calderón (2009), p.273.

${ }^{65}$ P. Calderón (2009), p.279.

${ }^{66}$ P. Calderón (2009), p.284.

${ }^{67}$ P. Calderón (2009), p. 303.
} 
de Lidoro, quien deseaba rescatar a su padre de la prisión. A su vez, estas sospechas corresponden a los pocos cortesanos que las notaron, pues el pueblo era engañado por el parecido físico entre madre e hijo. Sin embargo, estos nada podían hacer, tal como lo analizó Maquiavelo:

Los hombres, en general juzgan más por los ojos que por las manos, porque el ver pertenece a todos, pero el palpar a pocos. Todos ven lo que pareces, pocos palpan lo que eres, y esos pocos no se atreven a oponerse a la opinión de muchos que cuentan en su defensa con la majestad del estado [...]. Procure entonces un príncipe vencer y conservar el estado: los medios que utilice siempre serán juzgados como honrosos y elogiados por todos, porque el vulgo siempre se atiene a las apariencias y a lo que sucede, y en el mundo no hay más que vulgo; y los pocos no tiene lugar en él, cuando la mayoría tiene dónde apoyarse ${ }^{68}$.

Sin embargo, debemos notar que, pese al predominio de la apariencia, el accionar de ambos gobernantes es diametralmente opuesto, tal como lo podemos comprobar si analizamos la actuación pública de Ninias. En efecto, el príncipe valoraba a los consejeros prudentes como Lisías: "tu prudencia, en el mar de mi fortuna / piloto ha de ser de aquesta / nave ${ }^{69}$ "; se conmovió por la humillación de Lidoro, tratado como un perro, "[...] enternecido / me han dejado tus fortunas / y aún me ha parecido indigno / que así al vencido se trate ${ }^{70}$ "; no quiso la guerra en Siria; etc. Era, pues, un príncipe prudente y benévolo, diametralmente opuesto a la mítica reina.

Finalmente, Semíramis fue derrotada por Irán. Ella interpretó su caída como el resultado de una puja sobrenatural: "[...] en fin, Diana, has podido / más que la deidad de Venus, / pues sólo me diste vida / hasta cumplir los severos / hados ${ }^{71}$ " . A diferencia de Segismundo, la reina no se convirtió, sino que sucumbió a su pasión por el poder. En el plano terrenal, esta derrota trajo dos consecuencias importantes: por un lado, la muerte de la reina acosada por sus fantasmas, lo cual generó un sentimiento de compasión y temor, tal como Aristóteles (2003) lo enseñó en su Poética al tratar sobre la tragedia; por el otro, la reposición de Nínias en el trono. Al fin, la justicia triunfó sobre la fortuna.

En un plano filosófico y político, la reposición del hijo de la heroína en el gobierno significó el triunfo del modelo de rey justo, tal como lo esbozaron los Espejos de Príncipes de la Edad Media. A este modelo de gobernante lo podemos constatar en El Espejo de Príncipe del jurista valenciano Pedro Belluga Tous ${ }^{72}$ :

${ }^{68}$ N. Maquiavelo (2008),p. 163.

${ }^{69}$ P. Calderón (2009), p.246

${ }^{70}$ P. Calderón (2009), p.235.

${ }^{71}$ P. Calderón (2009), p.319.

72 Pedro Belluga Tous (1400-1468). Jurista valenciano, formado en la universidad de Bolonia, donde obtuvo los doctorados en Derecho Civil y en Derecho Canónico. Sirvió como abogado a los reyes de Aragón, Alfonso V y Juan II. Su Speculum Principum fue 
"[...] Dios os ha persuadido y aconsejado para que sostengáis la justicia delante de las leyes y los pactos sancionados con el pueblo ${ }^{73}$ ". Principalmente, se consideraba que la clemencia: "[...] es la que salvaguarda siempre a un rey, el amor hacia los ciudadanos es el único bastión inexpugnable ${ }^{74,}$. Esta virtud y este sentimiento estuvieron ausentes en el accionar de Semíramis. Asimismo, estas consideraciones sobre los sentimientos del monarca para con sus súbditos, contrastan con el pensamiento de Maquiavelo, quien aconsejó al príncipe que es mejor ser temido que amado. Como podemos observar, Calderón apostó por el modelo medieval de gobernante justo, benévolo y clemente. Por otra parte, la rebelión popular manifiesta la presencia de las ideas políticas del jesuita Francisco Suárez, quien, en su conocido tratado jurídico político Defensa Fidei, sostuvo que: "ningún rey o monarca recibe o ha recibido (de ley ordinaria) el poder político directamente de Dios o por institución divina, sino mediante la voluntad y la constitución humana $^{75 \%}$. En este sentido, no debemos olvidar que, en el siglo XVII, en Inglaterra, se gestó la primera revolución liberal que transformó la monarquía absoluta en parlamentaria.

Debemos tener en cuenta que Calderón no fue un revolucionario, sino un ferviente monárquico, fuertemente consustanciado con la causa de los Austrias. No obstante, él anheló un poder más justo, signado por los valores éticos. Este contrastó con las desmedidas ambiciones de poder y la corrupción imperante en su época.

\section{Conclusión}

Como hemos podido observar, en las dos obras dramáticas se manifestaron concepciones políticas opuestas. En este sentido, en la escena calderoniana estuvo presente el debate sobre el poder y sus límites, magistralmente sintetizados en dos modelos de príncipes: el esbozado por Maquiavelo en su obra más famosa, y el sustentado por la filosofía estoica y el pensamiento político medieval, el que, fundamentalmente, concibió a la potestad regia como la encarnación de lo justo.

Asimismo, en ambas obras teatrales triunfó la imagen del gobernante justo y prudente, la cual contrastó con la corrupción y el apetito de poder imperante en la época de los Austrias Menores, signada por una decadencia irreversible, que se manifestó tanto en el plano político, como en el moral. Pese a la crisis, se deseó instalar en el imaginario colectivo la efigie de un poder justo. Este anhelo nos habla de un deseo de superación: tenemos estos gobernantes, pero podríamos tener otros

escrito entre 1437 y 1441. Estuvo dedicado al rey Alfonso, el Magnánimo. Tuvo amplia difusión en los siglos XVI y XVII. En el texto se puede observar la transición jurídica y política del feudalismo al nacimiento del Estado Moderno.

${ }^{73}$ P. Belluga Tous (2000), p.19.

${ }^{74}$ P. Belluga Tous (2000), p.19.

75 F. Suárez (1967), p. 36. 
mejores, porque somos de esta forma, aunque tendríamos que ser de otra, más humana y fraternal. Así, pues, ellos, pese a todo, sostuvieron un ideal. En este sentido, cabe que nos preguntemos si este es el nuestro, pues también anhelamos ser gobernados por dirigentes justos y prudentes.

\section{Obras citadas}

Alcalá ZAMORA Y QUeIPo DE Llano, J.: Estudios Calderonianos, Madrid, Real Academia de la Historia, 2000.

AlthuSSER, Louis: Maquiavelo y nosotros, Madrid, Akal, 2004.

AQUINO, Tomás de: Opúsculo sobre el gobierno de los príncipes, México, Porrúa, 1996.

ARAngio Ruiz, Vicenzo: Historia del Derecho Romano, trad. de Francisco de Pelsmaeker e Ivañez, Madrid, Reus, 1980.

ARELLANO, Ignacio: "Decid al rey cuanto yerra. Algunos modelos del mal rey en

Calderón”, El teatro clásico español a través de sus monarcas (2006), pp.171-194.

ARISTÓTEles: Política, trad. de Manuela García Valdés, Madrid, Gredos, 1999.

-----: Poética, trad. de Eilhard Schlesinger, Buenos Aires, Losada, 2003.

-----: Ética Nicomaquea, trad. de Julio Pallí Bonet, Barcelona, Gredos, 2008.

Belluga Tous, Pedro: Espejo de Príncipe, trad. Ángels Calderó i Cabré, Barcelona, Estrategia Local, 2000.

Bodin, Jean, Los seis libros de la República, trad. de Pedro Bravo Gala, Madrid, Tecnos, 1997.

CALderón DE LA BARCA, Pedro: La vida es sueño, Madrid, Clásicos Castalia, 2003.

-----: La hija del aire, Madrid, Cátedra, 2009.

Del VeCCHIO, Giorgio: Filosofía del Derecho, Barcelona, Bosch, 1942.

FOUCAULT, Michel: "Omnes et singulatium: hacia una crítica de la razón política",

¿Qué es la Ilustración?, (1996), pp.17-66.

GRACIÁN, Baltasar: El héroe, El político Don Fernando, Madrid, Edaf, 2009.

HeLler, Herman: Teoría del Estado, México, Fondo de Cultura Económica, 1983.

KANTOROWITZ, Ernst: Los dos cuerpos del rey, trad. de Susana Aikin y Rafael Blázquez Godoy, Madrid, Alianza, 1985.

Maquiavelo, Nicolás: El Príncipe, trad. de Roberto Raschella, Buenos Aires, Losada, 2008.

MARAVAll, José Antonio: "El proceso de secularización en la España de los Austrias", Revista de Occidente,88 (1970), pp. 61-99.

-----: Estado Moderno y Mentalidad Social Tomo I, Madrid, Revista de Occidente, 1972. 
-----: Estudios de Historia del Pensamiento Español, Madrid, Ediciones de Cultura Hispánica, 1984.

Mirandola, Pico della: Discurso sobre la dignidad del hombre, Buenos Aires, Winograd, 2008.

POPPENBERG, George: "Política de amor. Los afectos y el poder en algunos dramas de Calderón", Anuario Calderoniano I,( 2011), pp. 283-295.

PROFETI, María G. Primera y segunda parte de "La hija del aire": significación y coherencia interna. Universidad de Zurich, 2010.

RIVADENEIRA, Pedro de: Tratado de la religión y virtudes que debe tener el príncipe cristiano, Madrid, Tecnos, 1998.

SAAVEDRA FAJARDO, Diego: Idea de un príncipe cristiano representada en cien empresas, Madrid, La Lectura, 1927.

STEIN, George: El derecho Romano en la historia de Europa, Trad. de César Hornero Méndez y Armando Romanos Rodríguez, Madrid, Siglo Veintiuno, 2001.

StrosetzKI, Christoph: "La filosofía política, el tacitismo español y Calderón", Calderón y el pensamiento y la cultura de su época,(2005), pp. 533-549.

SuÁrez, Francisco: Defensio fidei, trad. de Luciano Pereña, Buenos Aries, Depalma, 1966. 